Interactive comment on "A Tri-Approach for Diagnosing Gridded Precipitation Datasets for Watershed Glacio-Hydrological Simulation in Mountain Regions" by Muhammad Shafeeque and Luo Yi

Muhammad Shafeeque and Luo Yi

luoyi@igsnrr.ac.cn

Received and published: 21 October 2020

1 General Comments

Thank you very much for the positive assessment of our manuscript. The comments and suggestions are constructive to improve the presentation of the article. We will consider and incorporate these suggestions into the revised version of the manuscript. Following is the early point to point response to the comments and suggestions: 
The physical diagnosis aims to determine whether a basin can be considered plausibly realistic using a water-energy balance.

The approach is simple and easy to apply with observed physical data (discharge, precipitation, evapotranspiration). These data are usually frequently available because, in every catchment, these data are measured regularly (Andréassian and Perrin, 2012). The potential evapotranspiration is calculated using temperature and other physical data, representing the surface energy balance.

The Budyko theory-based equations describe the relationship primarily between the natural precipitation and evapotranspiration, while neglecting the changes in water storage in a watershed. This is generally a very good approximation for the non-glacierized watershed over the annual or inter-annual scale. However, for the glacierized watershed, it may fail. It is right the weakness of this approximation for the non-glacierized watershed that can be used as a tool for identifying if the water balance of a watershed is involved by the glacier melt as an additional input.

The Truc-Budyko equation assists in identifying the physical realism of the catchment under a particular precipitation dataset. In glacierized catchments, meltwater also plays a vital role in overall water balance. Baseflow contributions to the total runoff (Alley et al., 2002; Andermann et al., 2012; Savoskul and Smakhtin, 2013) compensate for the loss due to the groundwater percolation balance; therefore, the only imbalance in water balance would be due to meltwater (Immerzeel et al., 2015). Hence, the 'gaining' catchments highlight the meltwater contributions to the total runoff, whereas, the 'leaky' catchments can highlight the positive mass balance or glacier advance. The water balance equation, which has a mass balance component (Eq. 8), helps the actual under- or over-estimation in the selected/included GPDs, quantitatively.

Therefore, we are hesitated to remove this component from the Three-stage diagnosis approach. We hope it can be kept. Yet, we need to make further efforts in the composition of this section. We will present this part more clearly and concisely. Meanwhile,

Printer-friendly version

Discussion paper 
we will make our efforts to concise the whole manuscript.

3 Minor Suggestions

\section{Suggestion 1:}

I should note that I was not able to see any of the figure or table references in the manuscript, which may have led to some misunderstandings on my part.

\section{Response:}

We are extremely sorry for the inconvenience. The in-text references of figures and tables were misplaced while moving figures and tables to the bottom of the text. We will update the references in the revised version.

\section{Suggestion 2:}

Given that not all readers will necessarily be familiar with the statistical plots presented here, it would be useful to have more information in the figure captions, and to define the acronyms used in the figures. E.g. for figure 8 "the boxes represent ....." e.g. for figure 10 "each dot represents .... (an average/total for one year of data?)".

\section{Response:}

Thank you for the suggestions. The figure captions will be updated in the revised version, as suggested.

\section{Suggestion 3:}

Throughout the manuscript, the authors should check that acronyms and abbreviations are defined where they first appear, and consider repeating these, or providing a nomenclature. For example on line 95, Q, P, ET_p all need defining, on line 210 ETCCDI needs defining.

Response:

Thank you. We will improve the statement of acronyms and abbreviations. 


\section{Suggestion 4:}

Line 174: Was this adjusted using the same wind data as used in Dahri 2018? I think given the importance of this adjustment, an extra line explaining it would be useful.

\section{Response:}

The precipitation was adjusted based on the procedure and correction factors in Dahri et al. (2018). We will add this explanation of the procedure in the revised manuscript.

\section{Suggestion 5:}

Line 300: Please add references to the sentence 'The observed mass balance data were extracted from the literature'. Response:

Thank you for the suggestion. The references are also provided in the Table 2. We will add references in the main text too.

\section{Suggestion 6:}

Line 305: Where is the data from Besham Qila held or is there a reference for this data?

\section{Response:}

The discharge data at Besham Qila was collected from the Water and Power Development Authority (WAPDA), Pakistan. The reference for the data is provided in Table 2. The data from WAPDA are also acknowledged in the acknowledgment section.

\section{Suggestion 7:}

Line 323/Figure 5: Could you plot the points of the stations onto the map in figure 5 so it's easier to compare the observations and colour maps? More importantly, please switch the colour scheme for either figure 3 or 5 so that they are the same, with the same scale (a divergent colour scheme for both would make it clearer which areas are high precipitation and which are low precipitation). It's tricky to compare them when

Printer-friendly version

Discussion paper 
blue is dry regions in one plot and wet regions in the other.

\section{Response:}

Thank you very much for your constructive suggestions. We will update the Figure 3 and Figure 5 following your suggestions. In revised figures blue will represent the wet regions.

Suggestion 8:

Line 326: While it's clear what you mean here, I think technically this should be 'the GDPs did not show statistically significant trends', as you cannot generally use statistical tests to prove a lack of trend.

\section{Response:}

Thank you for your suggestion. We will update the sentence in the revised version, as suggested.

\section{Suggestion 9:}

Line 331-333: Are these discussions about bias coming from the Taylor diagram in figure 6 ? It might be better to talk about RMSE, as that's what you have shown here in figure 6 .

\section{Response:}

Thank you very much for your suggestion. We will update the explanation of Figure 6 in the text focusing on RMSE.

\section{Suggestion 10:}

Line 333: word missing '.....as the better in UIB...' -> '... as the better model in the UIB...'

\section{Response:}


Thank you for the correction.

Suggestion 11:

Line 345: It would be good to emphasize that this under/overestimation is particularly true during the winter, as it's interesting that these datasets appear to represent the summer monsoon much more effectively than the winter westerlies.

\section{Response:}

Thank you for the suggestion. We will update the explanation in the revised manuscript, as suggested.

\section{Suggestion 12:}

Lines 349-355: You could consider cutting figure $7 \mathrm{~b}$ and the accompanying text, as I think this is all shown in figure $7 \mathrm{a}$ and that discussion. If figure $7 \mathrm{~b}$ is kept, could the seasons be put in order? l'd recommend Winter, spring, summer, autumn as this will make it easier to see the winter and spring precipitation together.

\section{Response:}

Thank you. We will update the figure $7 \mathrm{~b}$ in the revised version by re-ordering the seasons as recommended.

\section{Suggestion 13:}

Lines 357-368: It's not quite clear how these numbers relate to figure 8, or how the values in figure 8 and the numbers in the text are calculated. Are the mean and standard deviations given in the text taken from each year? I.e. the maximum CDD taken from a year, and then averaged over all the years? Given figure 8 shows the median and 25th/75th percentiles, it might be more useful to discuss those? (although presumably the red dots are the means in each case).

Response: 
Thank you for highlighting it. Yes, the maximum CDD was taken from a year, and then averaged over all the years. Meanwhile, we will improve the presentation by discussing the boxplots' statistics (the median and 25th/75th percentiles).

\section{Suggestion 14:}

Figure 9/lines 372-382: is the runoff value the same for each of the models? Is this a measured value? Please state in the text and the figure caption.

\section{Response:}

Yes, the observed runoff values are the same for each model. We will add an explanatory statement here for clarity.

\section{Suggestion 15:}

Lines 383-391: This section discusses correlation between runoff and precipitation. However given there is no significant correlation between the observed precipitation and runoff, except in the Karakoram, it seems that there may be other factors that need to be taken into consideration, and therefore that correlation between these two variables probably should not be used to judge the datasets?

\section{Response:}

Thank you for highlighting an important point. The correlation between precipitation and runoff may not represent the validity of a precipitation dataset, and thus, should not be used alone to judge the datasets. This motivates to use 'physical diagnosis' for determining the physical realism of a catchment under different precipitation datasets. We also used a water balance equation (Eq. 8), including the mass balance component, to assess a precipitation datasets' validity.

Suggestion 16:

Line 456: Are these six SPHY model runs identical, except for the precipitation dataset used? Or are there some differences, apart from the precipitation datasets? 
Yes, these six SPHY models are almost identical to the base calibrated model. There was a little tuning of DDFs for ice and snowmelt to keep the average mass balance closer for all the precipitation datasets. This was done to compare the rationality of the mass balance and streamflow outputs.

\section{Suggestion 16:}

Line 494-497: I don't quite understand this.

\section{Response:}

The rationality of runoff and mass balances simultaneously means that the simulated runoff and mass balance represent the actual situation (observed values) in the catchment at the same time. As the datasets are under- or over-estimated; therefore, one of these two variables (runoff or mass balance) will be under- or over-estimated accordingly (i.e., in simulated).

\section{Suggestion 17:}

Line 510: Could you add some references here?

\section{Response:}

Several researchers have evaluated the precipitation datasets using simple statistical methods (Ali et al., 2017; Anjum et al., 2018; Blacutt et al., 2015; Henn et al., 2018; Hu and Chen, 2018; Hu et al., 2016; Hussain et al., 2017; Romilly and Gebremichael, 2011). However, when the observed data do not represent a catchment's entirety, then such simple statistical methods may not provide the true assessment of precipitation datasets. The data is not sufficient (a small number of stations) and not sufficient quality (uneven distribution of stations - mostly at lower elevations) (Winiger et al., 2005). Several other researchers also pointed out these limitations in previous studies (Dahri et al., 2018; Immerzeel et al., 2015). 


\section{Suggestion 18:}

Line 589-594: you suggest undercatch in the observations here as a reason for the unbalanced water balance, but haven't you already corrected for this?

\section{Response:}

In several gridded datasets, observed precipitation (uncorrected) is used, for example, APHRODITE (Yatagai et al., 2012). Therefore, it can be argued that the undercatched precipitation (in GPDs) might be a reason for an unbalanced water balance. The adjusted average precipitation in UIB represents a plausible water balance.

\section{Suggestion 19:}

Lines 595-598: is increasing glacier mass balance also a reason for a 'leaky' catchment?

\section{Response:}

Yes, it is. A part of precipitation is lost to keep the mass balance increasing (positive mass balance/glacier advance). That missing (frozen) water is not contributing to the total runoff at the moment. So, the energy balance goes beyond the limits and makes the catchment 'leaky'. We will incorporate the suggestion. Thank you.

Suggestion 20:

Line 613: repetition of the underestimated GPDs.

\section{Response:}

Thank you for highlighting. We will fix it in the revised version.

\section{Suggestion 21:}

Figure 6: please keep the colours for each model matching to those in figure 5. 
Thank you for the suggestion. We will fix this in the revised Figures.

Suggestion 22:

Figure 14: What's the difference between a and c? Does figure e include the glacier cover, or is it only snow cover? If it's only snow cover, I don't see how in figure (e) MODIS and SPHY look so similar for august, when the snow cover (green only) look quite different in $b$ and $d$.

\section{Response}

In Figure 14, 'a' is the MODIS maximum snow cover in March, and 'b' is SPHY maximum snow cover in March. The snow cover is slightly different in the two maps. Most of the differences are spotted at low elevations over the southeast and southwest parts. The glacier cover is also included in figure part 'e'.

We are grateful for your precious time, positive assessment, and constructive suggestions. These will improve the presentation of the research article.

\section{Sincerely,}

Yi Luo and Muhammad Shafeeque

\section{References}

Ali, A. et al., 2017. Evaluation and Comparison of TRMM Multi-Satellite Precipitation Products With Reference to Rain Gauge Observations in Hunza River Basin, Karakoram Range, Northern Pakistan. Sustainability, 9(11): 1954-1972. DOI:10.3390/su9111954

Alley, W.M., Healy, R.W., LaBaugh, J.W., Reilly, T.E., 2002. Flow and storage in groundwater systems. Science, 296(5575): 1985-90. DOI:10.1126/science.1067123

Andermann, C. et al., 2012. Impact of transient groundwater storage on the discharge of Himalayan rivers. Nature Geoscience, 5(2): 127-132. DOI:10.1038/ngeo1356 
Andréassian, V., Perrin, C., 2012. On the ambiguous interpretation of the TurcBudyko nondimensional graph. Water Resources Research, 48(10): W10601. DOI:10.1029/2012wr012532

Anjum, M.N. et al., 2018. Performance evaluation of latest integrated multisatellite retrievals for Global Precipitation Measurement (IMERG) over the northern highlands of Pakistan. Atmospheric Research, 205(October 2017): 134-146. DOI:10.1016/j.atmosres.2018.02.010

Blacutt, L.A., Herdies, D.L., de Gonçalves, L.G.G., Vila, D.A., Andrade, M., 2015. Precipitation comparison for the CFSR, MERRA, TRMM3B42 and Combined Scheme datasets in Bolivia. Atmospheric Research, 163: 117-131. DOI:10.1016/j.atmosres.2015.02.002

Dahri, Z.H. et al., 2018. Adjustment of measurement errors to reconcile precipitation distribution in the high-altitude Indus basin. International Journal of Climatology, 38(10): 3842-3860. DOI:10.1002/joc.5539

Henn, B., Newman, A.J., Livneh, B., Daly, C., Lundquist, J.D., 2018. An assessment of differences in gridded precipitation datasets in complex terrain. Journal of Hydrology, 556: 1205-1219. DOI:10.1016/j.jhydrol.2017.03.008

Hu, Z., Chen, D., 2018. Evaluation of three global gridded precipitation data sets in central Asia based on rain gauge observations. (February): 1-19. DOI:10.1002/joc.5510

Hu, Z., Hu, Q., Zhang, C., Chen, X., Li, Q., 2016. Evaluation of reanalysis, spatially interpolated and satellite remotely sensed precipitation data sets in central Asia. Journal of Geophysical Research: Atmospheres, 121(10): 5648-5663. DOI:10.1002/2016jd024781

Printer-friendly version

Hussain, S. et al., 2017. Evaluation of gridded precipitation data in the Hindu KushKarakoram-Himalaya mountainous area. Hydrological Sciences Journal, 62(14): 2393-2405. DOI:10.1080/02626667.2017.1384548 
Immerzeel, W.W., Wanders, N., Lutz, A.F., Shea, J.M., Bierkens, M.F.P., 2015. Reconciling high-altitude precipitation in the upper Indus basin with glacier mass balances and runoff. Hydrology and Earth System Sciences, 19(11): 4673-4687. DOI:10.5194/hess-19-4673-2015

Romilly, T.G., Gebremichael, M., 2011. Evaluation of satellite rainfall estimates over Ethiopian river basins. Hydrology and Earth System Sciences, 15(5): 1505-1514. DOI:10.5194/hess-15-1505-2011

Savoskul, O.S., Smakhtin, V., 2013. Glacier systems and seasonal snow cover in six major Asian river basins: hydrological role under changing climate, 150. IWMI.

Winiger, M., Gumpert, M., Yamout, H., 2005. Karakorum-Hindukush-western Himalaya: assessing high-altitude water resources. Hydrological Processes, 19(12): 2329-2338. DOI:10.1002/hyp.5887

Yatagai, A. et al., 2012. APHRODITE: Constructing a Long-Term Daily Gridded Precipitation Dataset for Asia Based on a Dense Network of Rain Gauges. B Am Meteorol Soc, 93(9): 1401-1415. DOI:10.1175/BAMS-D-11-00122.1

Interactive comment on Hydrol. Earth Syst. Sci. Discuss., https://doi.org/10.5194/hess-2020194, 2020. 